\title{
The Design and Implementation of a Mathematics Learning Community
}

\author{
Alexandra Kurepa ${ }^{1}$ \\ ${ }^{1}$ Department of Mathematics, North Carolina A\&T State University, Greensboro, NC, USA \\ Correspondence: Alexandra Kurepa, Department of Mathematics, North Carolina A\&T State University, Greensboro, \\ NC 27411, USA. E-mail: kurepa@ncat.edu
}

Received: March 15, 2018

Accepted: May 8, 2018

Online Published: May 10, 2019

doi:10.5430/ijhe.v8n3p77

URL: https://doi.org/10.5430/ijhe.v8n3p77

Supported by the National Science Foundation grant award DUE \# 125990

\begin{abstract}
We describe the design and implementation of the Mathematics Learning Community structured as a cohort-based and faculty-mentored group composed mostly of underrepresented minority students in mathematics. The Mathematics Learning Community's goals are: (i) to increase the number of students majoring in mathematics at both the undergraduate and graduate levels, (ii) to improve the retention and completion rates, and (iii) to increase the number of students pursuing advanced degrees in mathematics. The design is innovative in a number of ways including its focus on a single discipline, its inclusion of both graduate and undergraduate students in the same learning community, and the use of student vertical tutoring, and faculty mentoring, among other things. The inclusion of upper-level students appears to have reduced the unintended negative effects of typical student-centered learning communities. Although the program is relatively new, the Mathematics Learning Community has been successful by a number of different measures.
\end{abstract}

Keywords: learning communities, peer learning and mentoring

\section{Introduction}

In recent years, considerable attention has been devoted to the theoretical concept of learning communities and to their practical implementation. This work has ranged from investigations at the elementary level by Bryk, Camburn \& Luis (1999), middle-school level by Thompson, Gregg \& Niska (2004), and high school levels for teachers and administrators by Walker (2016), Clauset, Lick \& Murphy (2008), and Max (2005), to groups whose core consists of university students by Zhao \& Kuh (2004), Price (2005), Otto et al. (2015) and to university faculty levels by Engin $\&$ Atkinson (2015). Smith (2001) gives a brief history of learning communities and argues that they have become a national movement. While Price (2005) argues that,

The learning community "movement" has grown in large part because of the leadership and advocacy of the Washington Center for Undergraduate Education at Evergreen State College. Founded in 1985, the Washington Center expanded its support for learning communities after 1996 with support from the Fund for the Improvement of Postsecondary Education (FIPSE) and the Pew Charitable Trusts. As of August 31, 2005, more than 245 learning communities were listed in the online directory of the National Learning Commons (p.1).

Otto et al. (2015) give an overview of the types of learning communities in higher education. Work by Inkelas et al. (2018) attempts to give a guide on effective development and assessment of such living- learning communities. Currently, there are more than 280 universities or colleges of some type listed at the Washington Center website as having some type of learning community. Price (2005) goes on to describe the literature related to the effectiveness of learning communities.

Alongside the increasingly widespread use of learning communities by colleges and universities, a literature on their effectiveness is emerging. Much of this research consists of single-institution assessment reports and qualitative case studies; however, a few quasi-experimental and correlative research studies indicate that students who participate in learning communities get better grades and re-enroll in subsequent terms at rates higher than their peers who take stand-alone academic courses. Recently, early data from a learning communities evaluation provided more robust 
evidence of their impact on student success (p.1).

One of the uses to which learning communities in the STEM disciplines can be put is an attempt to apply those techniques to the problem of underrepresented minorities in STEM. Various sources including the US government have noted for some time that the number of minorities entering the STEM disciplines, including mathematics, is far below the numbers that would correlate with the percentage of the population constituted by those minorities.

One measure of the representation of minorities within mathematics in the United States is the data on recently granted doctoral degrees. The American Mathematical Society reports that during the 2014-2015 academic year, universities in the United States awarded 1,901 doctorates in mathematics. Of that amount, only 880 went to US citizens. Of those 880,244 (27.7\%) were awarded to women. Only 20 out of 880 were awarded to African Americans (10 men and 10 women), which is $2 \%$ of the graduates with US citizenship and only $1 \%$ of the total degrees awarded in the US. Only 26 of 880 were awarded to Hispanics or Latinos, or $3 \%$.

Another measure of the representation of minorities within mathematics in the United States is the data on recent recipients of BS degrees in mathematics.

Barr, Maxwell \& Velez (2016) show that the percentage of underrepresented minority students obtaining a BS degree in mathematics has increased by $2 \%$ and that in 2013 it was $13.5 \%$ of total number of degrees granted to US students.

Various projects have attempted to employ learning communities as one of a group of strategies aimed at improving the numbers of underrepresented minorities in the STEM disciplines. The project described here aims specifically at improving those numbers within the field of mathematics.

Zhao \& Kuh (2004) provide evidence for the effectiveness of learning communities in increasing student satisfaction. However, as early as 2001, Smith (2001), while lauding learning communities, noted a number of challenges for those types of groups including the challenge of maintaining diversity.

Jaffee (2007), while noting the evidence for positive results related to learning communities such as Tinto (2000) also pointed out that learning communities can actually be counterproductive in certain ways. Like Smith (2001), he cites the diversity issue as causing potential serious problems.

The very conditions of homogeneity and extended association that should promote community - a relatively small group of post-adolescent freshman-age students taking a cluster of classes together - can also recreate a mutually reinforcing high-school like environment with the associated demeanors and behaviors. This is one of the most immediately noticeable unintended consequences routinely reported by students and faculty. Ironically, the high school environment might be less likely to emerge if there were a more age-heterogeneous, but potentially less cohesive, population that could afford the newly arrived freshmen the opportunity to interact with older, more mature and often more academically serious, students. Such informal "near-peer" support, mentorship, and role modeling is unavailable in the FLC classroom. Rather, students find themselves in an environment that closely resembles their high school classroom and they, therefore, may employ high school student scripts and norms. Thus, a structural arrangements designed to prepare and socialize students in the transition to college life may inadvertently create conditions that potentially prevent or retard their academic development (p.67).

Walker's (2016) work on mathematics learning communities in the urban high school gives insights into the role of peer interaction in the learning process. Walker argues that "broad mathematics opportunities afforded by learning communities extend beyond peers' focus on school mathematics".

\section{Design and Implementation}

As described below, this particular implementation of a learning community attempts to avoid this specific problem through an alternative structure for the learning community.

\subsection{Goals}

Designing the Mathematics Learning Community has three major goals and a secondary goal. The first goal is to increase the number of students majoring in mathematics at both the undergraduate and graduate levels. One of the intended benefits of this goal is to improve the educational environment for both the students in mathematics and those students in other STEM disciplines by giving those students a larger group of colleagues with whom to interact. More information on the specifics of that advantage can be found below. 
The second goal is to increase the number of underrepresented minorities in the STEM disciplines. The number of underrepresented minorities in the STEM disciplines is strikingly low and those students remain a drastically small percentage of all students majoring in STEM areas. We believe that the Mathematics Learning Community constitutes one technique for improving the situation.

The third goal of the program is to improve the retention and completion rates of all students in the STEM programs and especially the underrepresented minorities. Improving the retention and completion rates of students in STEM disciplines remains crucial to achieving the goals of both higher education and of the society as a whole.

The secondary goal is to reduce the likelihood of one of the potential unintended consequence of homogeneity, namely a slower maturation process.

\subsection{Objectives}

One problem relates to all three of these goals. We term that problem the "disconnect problem." The "disconnect problem" concerns the lack of deeper discipline understanding students often express with regard to their major field of study. Many courses are taught as a series of lectures and students are given little or no time to discuss, absorb and investigate topics outside the classroom. In order to alleviate this problem, the Mathematical Learning Community is designed to connect student learning with opportunities to place learning in context and to allow the students to connect their academic and social lives. Solving the disconnect problem entails bringing together students who are peers and "near peers" so that younger students see the kinds of work expected of more experienced students and the maturity with which those older students handle the responsibilities.

\subsection{Organization and Implementation}

The implementation of the Mathematics Learning Community involves the building of a mathematical cohort, an important role for the faculty outside the classroom, and several unique attributes. The subsections below detail the main elements of the program and the relationship of those elements to one another.

The development and implementation of the Mathematics Learning Community is supported by the NSF S-STEM Program. The Learning Community involves up to 25 students -- first-year students through graduate students with roughly five at each level. The core of the Community involves math majors only. Students engage in project work including research and other enrichment activities. Problem sessions and study teams are available as is vertical tutoring and mentoring. Participation in seminars, special lectures, and technology topics is encouraged and advisement and assistance is offered to those applying for REU programs and internships.

Faculty participation in the program was secured in the grant application process with co-PIs and other faculty members understanding that their role would be to take part in the vertical mentoring of these students. Student participation in vertical mentoring and the other parts of the program were required as part of acceptance to the program and funding.

\subsection{Faculty Role}

After careful advising, students are placed in certain course sections. Experience indicates that students in the same section of a course tend to network with each other outside of the classroom. That networking facilitates the activities planned by the faculty as well as the tutoring and problem sessions. One of the main goals of the faculty involved with the program is to organize activities and supporting services in such a way as to encourage student participation and interaction. These activities and supporting services are intended to promote self-development and self-confidence.

At each of the five levels, from first-year students through graduate students, there are two faculty members assigned to help mentor the students, to coordinate the activities of the students, and to help monitor their academic progress and mathematical development. In addition to the formal advisor assigned by the department to each student, the faculty members involved in the S-STEM project informally advise students if problems have been noticed with the students' in-class performance. These faculty members design a study/tutoring guide to help the student experiencing difficulties. Then, with the help of a student further along in the degree program, the mentor and tutor work on improving the grades for the troubled student. Faculty and students associated with the Mathematics Learning Community participate regularly in the Annual Math Awareness Day mini-conference to present their research and to discuss the findings of the project.

\subsection{Unique Attributes}

Five attributes of this particular Mathematics Learning Community stand as unique aspects of the program when compared to other learning communities devoted to the STEM disciplines. First, the Community focuses on a single 
discipline. Second, the students must be involved in vertical mentoring. Third, the Community requires that undergraduate and graduate students form a single group. Fourth, the Community provides a wide-range and combination of activities including mentoring, tutoring, enrichment, and research activities. Fifth, more than half of the departmental faculty members are involved in some way in the Community through advising and mentoring capstone projects, research projects and career development and placement.

It should be noted that this learning community does not conform to the generally accepted definition of a learning community in that the cohort includes more than a single year-group of students, such as only first-year students. Consequently, the Community does not conform to the idea of developing a cohort by forcing all of them into the same sections of the same courses. The cohort is formed by the outside-the-classroom activities, not by congruent classes.

\section{Findings}

Indicators of the success of the Mathematical Learning Community include the following statistics.

Over the course of the program, over 80 different students have participated in the program as Math S-STEM Scholars. The original intention was to maintain five students at each level of the program. Given the applicant pool and the requirements of the S-STEM grant, it was not always possible to keep exactly five students at each level. Nevertheless the program has maintained academic diversity with all classifications being represented at all times.

Since the implementation of the program, the one-year retention rate for undergraduate students has risen from $62 \%$ to over $77 \%$. The three-year retention rate rose from $46 \%$ to $53 \%$. Only $14 \%$ of the students in mathematics graduated in four years before institution of the program. In the first six years of the program, the four-year graduation rate rose to $38 \%$. Since the institution of the program the number of degree-seeking students at the undergraduate and graduate level have risen about 30\%. The department now typically graduates fifteen undergraduates per year and eight graduate students per year.

Over the past 5 years of the program, the retention rate for S-STEM Scholars participating in the Mathematics Learning Community has been $89 \%$. The five-year graduation rate for the undergraduate participants was $78 \%$. The three-year graduation rate for graduate students is $86 \%$. Of those who have graduated since the inception of the Mathematics Learning Community, $90 \%$ have come from underrepresented minorities, overwhelmingly African-Americans.

Enrichment activities, such as specialized lectures or guest lectures and projects that were directly tied to one of the courses in which the students were enrolled were much more successful than projects and lectures that were, or were perceived to be, outside the bounds of that particular semester's course offerings. This proved especially the case for students in the freshman through junior levels. At the senior level, the students showed themselves more mathematically independent, able, and interested in learning about and working on projects not directly related to their current course work.

Student projects that resulted in presentations at various conferences, or even simply as classroom presentations, were taken much more seriously by the students than projects that produced papers submitted to a professor. The students produced higher quality work than projects that were simply turned in to a particular professor.

The number of Math Learning Community scholars attending summer Undergraduate Research Experience programs (typically eight to ten week programs for which students travel to other universities around the United States) was $32 \%$. In addition, about $80 \%$ of the scholars participated in the Annual Math Awareness Day mini-conference presenting either a talk or a poster on their research.

One of the integral components of the Mathematics Learning Community was the development of vertical peer mentoring and tutoring which has proven to be very successful. Students participate in a tutoring lab and help each other. Since the program involves freshmen, sophomore, junior, and senior students as well as a few graduate students it was possible to organize the students into teams so that the more experienced students could mentor, advise, and tutor the less-experienced students.

The vertical peer mentoring also seemed to reduce or eliminate the incidence of the kind of transition problems and lack of maturity described by Jaffee (2007). The students seemed to realize quickly that mathematics is long road and that whatever level of talent one has, there is always more to learn. They seemed to understand that very soon they would be called upon to make presentations and that the projects and behavior of the more senior and graduate students represented serious role models for each of the younger students. 
The limiting of this program to a single discipline enabled the Learning Community to develop in a particular way. Mathematics Learning Community members became members of mathematics professional organizations and attended professional organization meetings and conferences. About $60 \%$ of the undergraduate scholars have gone on to graduate school, and $52 \%$ of the graduate students have gone on to a doctoral program after obtaining their masters degree. There was also a higher success rate for students attempting to enter prestigious graduate programs.

\section{Conclusion}

The Mathematics Learning Community has met the set goals. It has helped increase the number of underrepresented students in the mathematical sciences (pure and applied mathematics, and statistics) at both the bachelor's and master's levels. Retention, and graduation rates have improved and interest in furthering their education though a master's or PhD program has increased.

Beyond that, a number of other comments can be made and conclusions reached regarding other parts of the Learning Community's activities. These items relate to the enrichment projects, the student projects, the problem sessions, the vertical peer mentoring/tutoring, and the single discipline nature of the project.

In this environment, the enrichment projects need to be directly tied to class work and involve the instructor who teaches the related class in order for these enrichment projects to succeed.

To maintain high standards for student projects, faculty members must require students to make presentations at professional conferences. Encouraging students to deliver that kind of presentation improves the quality of the work in at least four ways. First, it causes the students to produce higher quality work. Second, the students become more supportive of their peers. Before the conference, they exhibit curiosity about the projects of their peers. At the conference, they attend the presentations of their peers. Third, they are more likely to take to heart the critiques of the presentations provided by the faculty prior to the conference. Fourth, they development a better understanding of the real work of a mathematician and accord that work more respect.

Regarding the problem sessions that were organized for members of the Learning Community and others who wished to join in, we can conclude that these problem sessions should be organized by the faculty and students together. Faculty participation in the organization of these sessions ensured that the sessions would be more formal than an impromptu student meeting and more productive. Student participation in the organization of the sessions ensured that a given session had a focus, but did not turn into another faculty lecture.

Vertical peer mentoring and tutoring was judged a success and became a procedure that accomplished two objectives while actually enhancing the students' professional development. First, the vertical peer mentoring and tutoring resulted in a more closely knit community within the department, not just amongst the grant-supported students. The peer vertical mentoring/tutoring of the students who received grant money served as a core of activity that eventually spread to other students within the department. Second, this type of mentoring/tutoring gave the students a greater sense of belonging to the profession as well.

The focus on a single discipline for this project helped develop student self-confidence, pride and appreciation for the discipline as well as for the students' major. Various math activities, such as attendance at mathematical meetings, membership in mathematical professional organizations, and work in the tutoring lab to help promote the learning of mathematics, has caused the students to become more closely connected with the faculty, the discipline and with each other.

\section{Acknowledgments}

This work was supported, in part, by a grant from the National Science Foundation S-STEM Program award DUE 125990. The author wishes to thank all of the faculty members who have worked with the Mathematics Learning Community.

\section{References}

American Mathematical Society. (2019). Annual Survey of the Mathematical Sciences: Doctorates Granted. Retrieved from http://www.ams.org/profession/data/annual-survey/docsgrtd

Barr, T. H., Maxwell, J. W., \& Velez, W. Y. (2016). Recent trends in Bachelors Degree recipients in Mathematics at US Institutions. Notices of the American Mathematical Society, 63(6), 660-665. 
Bryk, A., Camburn, E., \& Louis, K. S. (1999). Professional Community in Chicago Elementary Schools: Facilitating Factors and Organizational Consequences. Educational Administration Quarterly, 35(5), 751-781. https://doi.org/10.1177/0013161X99355004

Clauset, K. H., Lick, D. W., \& Murphy, C. U. (2008). Schoolwide Action Research for Professional Learning Communities: Improving Student Learning Through The Whole-Faculty Study Groups Approach. Thousand Oaks: Corwin Press.

Engin, M., \& Atkinson, F. (2015). Faculty Learning Communities: A Model for Supporting Curriculum Changes in Higher Education. International Journal of Teaching and Learning in Higher Education, 27(2), 164-174.

Jaffee, D. (2007). Peer cohorts and the unintended consequences of freshman learning communities. College Teaching, 55(2), 65-71. https://doi.org/10.3200/CTCH.55.2.65-71

Inkelas, K. K., Jessup-Anger, J., Wawrzynski, M., \& Benjamin, M. (2018). Living-Learning Programs that Work: A Research-Based Model for Design, Delivery, and Assessment. San Francisco: Stylus Publishing, LLC.

Engin, G. (n.d.). Professional Learning Communities: Guidance for High School Principals. Retrieved from www.allthingsplc.info/pdf/articles/easternmichiganuniversity.pdf

Otto, S., Evins, M., Boyer-Pennington, M., \& Brinthaupt, T. (2015). Learning Communities in Higher Education: Best Practices,. Journal of Student Success and Retention, 2(1), 1-20.

Price, D. (2005). Learning Communities and Student Success in Postsecondary Education. MDRC, 1-23.

Smith, B. L. (2001). The challenge of learning communities as a growing national movement. Peer Review, 4(1). https://www.aacu.org/publications-research/periodicals/challenge-learning-communities-growing-national-mov ement

Thompson, S., Gregg, L., \& Niska, J. (2004). Professional Learning Communities, Leadership and Student Learning. Research in Middle Level Education, 28, 1-15. https://doi.org/10.1080/19404476.2004.11658173

Tinto, V. (2000). What have we learned about the impact of learning communities on students? Assessment Update, 12(2), 1-2, 12. https://doi.org/10.1002/au.122

Walker, E.N. (2016). The importance of communities for mathematics learning and socialization. Journal of Urban Mathematics Education, 9(2), 5-10.

Washington Center at The Evergreen State College. (2019). Learning Communities. Retrieved from http://wacenter.evergreen.edu/learning-communities

Zhao, C. M., \& Kuh, G. D. (2004). Adding Value: Learning Communities and Student Engagement. Research in Higher Education, 45, 115-138. https://doi.org/10.1023/B:RIHE.0000015692.88534.de 